\title{
Autonomy, rights and children with special educational needs: the distinctiveness of Wales
}

Ware, Jean

\section{International Journal of Inclusive Education}

\author{
DOI: \\ 10.1080/13603116.2019.1580928
}

Published: 04/05/2019

Peer reviewed version

Cyswllt i'r cyhoeddiad / Link to publication

Dyfyniad o'r fersiwn a gyhoeddwyd / Citation for published version (APA):

Ware, J. (2019). Autonomy, rights and children with special educational needs: the distinctiveness of Wales. International Journal of Inclusive Education, 23(5), 507-518. https://doi.org/10.1080/13603116.2019.1580928

\footnotetext{
Hawliau Cyffredinol / General rights

Copyright and moral rights for the publications made accessible in the public portal are retained by the authors and/or other copyright owners and it is a condition of accessing publications that users recognise and abide by the legal requirements associated with these rights.

- Users may download and print one copy of any publication from the public portal for the purpose of private study or research.

- You may not further distribute the material or use it for any profit-making activity or commercial gain

- You may freely distribute the URL identifying the publication in the public portal?
}

Take down policy

If you believe that this document breaches copyright please contact us providing details, and we will remove access to the work immediately and investigate your claim. 


\section{Autonomy, rights and children with special educational needs: the distinctiveness of Wales}

Recto running head : INTERNATIONAL JOURNAL OF INCLUSIVE EDUCATION

Verso running head : J. WARE

Jean Ware[AQ1]

School of Education and Human Development, Bangor University, Gwynedd, UK

CONTACT Jean Ware j.ware@bangor.ac.uk

Copyright Line: @ 2019 Informa UK Limited, trading as Taylor \& Francis Group

\section{ABSTRACT}

Wales was the first UK country to incorporate the UNCRC into domestic law and the first to appoint a children's commissioner. Wales is distinctive in the strong links between education and the promotion of the Welsh language as evidenced in successive Welsh language strategies. With regard to children with special educational needs, the 2018 Additional Learning Needs and Educational Tribunal Act makes provision for children's voices to be heard in their own right. This paper examines the complexities in hearing the voices of children with severe and profound learning difficulties (SPMLD), and how these can be 
addressed in the language context of Wales. It concludes that there are cautious grounds for optimism about our ability to hear the views of children with SPMLD, as long as we are prepared to acknowledge the resource implications. However, there is a need for more debate about the potential tensions between the Welsh language strategy and making provision for children with special educational needs in their preferred language. This debate needs to be informed by research on the impact of immersion education on progress, access to the curriculum and inclusion for children with SPMLD, and on their views about all aspects of their provision.

\section{KEYWORDS}

Wales; education; severe and profound learning difficulties; children's voices; Welsh language policy

\section{Introduction}

There are a number of ways in which Wales can lay claim to being innovative; it was the first country in the UK to incorporate the UNCRC into domestic law, and the first to appoint a children's commissioner. Since devolution, the education system in Wales has also become increasingly distinct, especially from that in England, to which it was closely tied in the past (SESC 2018). Arguably, the most significant of these differences is the place of the Welsh language within education and the role envisaged for education by the Welsh government in increasing the number of Welsh speakers (Welsh Government 2017a). Other distinctive features include an emphasis on community schools; there are no academies and no free schools in Wales, and all state secondary schools are comprehensives. There is also a smaller proportion of faith schools than in England, with faith schools comprising just $14 \%$ of schools in Wales in comparison with more than $30 \%$ in England. Compared with England and Northern Ireland, a higher proportion of children in Wales are identified as having SEN (22.6\%) (Welsh Government 2018a); this is unsurprising given the link between SEN and poverty (Wales is the poorest UK nation). In line with the emphasis on community schools, Wales has a strong emphasis on inclusion, with relatively large numbers of children with SEN in mainstream schools. A number of counties provide for many children with SEN in mainstream units at primary level, and there are also some secondary units, and although this form of provision may partly be driven by low population density, it may also be seen to reflect an inclusive ethos within Welsh education policy. This paper seeks to examine the way in which some of these distinctive characteristics interact to impact the extent to which children with SEN in Wales are able to exercise their rights and have their voices heard; and in particular how this applies to children with severe or profound learning difficulties (SPMLD) or very severe communication difficulties.

\section{The current context}

Education in Wales is currently undergoing a major period of change. One key impetus for these changes has been Wales' position within successive cycles of the PISA tests. It has been widely reported that Wales has performed the least well of the four home nations in each cycle since 2006, meaning that, on average children in Wales achieve lower scores than children in England, Scotland, or Northern Ireland. In the context of children's rights, however, as cautioned by Rees (2018) and the Innocenti group (Chzhen et al. 2018), it is worth remembering that average scores are only one way of looking at the PISA results, with the level of equality between children from different backgrounds being another important issue. On this measure, Wales outperforms the other home nations. Nonetheless, recent reviews of Welsh Education by the OECD (OECD 2014) and of the School Curriculum by Professor Graham Donaldson (Donaldson 2015) were commissioned by the government to address the headline PISA test results. A new approach to the school curriculum is currently being developed in response to the Donaldson report, and a new curriculum will be in place from September 2022.

At the same time, the system for supporting children with Special Educational Needs (SEN) is being revised. A new Additional Learning Needs and Education Tribunal (Wales) Act was passed in January 2018 (the ALNET Act), and a new Code of Practice for Additional Learning Needs (ALN) comes into effect from September 2020. A draft version of this code was published in 2017 (Welsh Government 2017b) and aspects of it are already being trialled in a number of schools.

In addition, there have been considerable developments in Welsh language policy since devolution. People who are not from Wales may not be aware of the strength of the Welsh language in Wales. Currently, around 19\% of the adult population speak Welsh (Welsh Government 2018a), and a substantial and growing proportion of children are educated wholly or partly through the medium of Welsh. In 2016, 16\% of children were in Welsh medium schools and a further $10 \%$ in schools which were either bilingual or where there was significant provision through the medium of Welsh. Welsh ([AQ2]as either a first or second language) is compulsory for all children up to the age of 16 (Jones 2016). The Welsh Government sees education as having a key role to play in realising its vision of a fully bilingual Wales. There have been a number of policy documents over the past two decades which emphasise this (WAG 2003; Welsh Government 2012a, 2017a). The most recent, and by far the most ambitious lays out a vision for more or less doubling the number of Welsh Speakers to one million by 2050 (Welsh Government 2017a).

\section{Severe and profound learning difficulties}


In order to understand the particular challenges involved in hearing the voices and views of children and young people with profound and multiple learning difficulties, it is necessary to define what is meant by profound and multiple learning difficulty. As Bellamy et al. (2010) point out there is no agreed definition of profound and multiple learning difficulties. One widely cited definition is that given by the PMLD Network according to which people with PMLD:

- Have more than one disability

- Have a profound learning disability

- Have great difficulty communicating

- Need high levels of support with most aspects of daily life

- May have additional sensory or physical disabilities, complex health needs or mental health difficulties

- May display behaviours that challenge us

- (PMLD Network, cited in MENCAP and the Challenging Behaviour Foundation, undated) 1

One thing that is emphasised in all discussions about the characteristics of people with PMLD is the great difficulty they have in communicating, which is of particular importance in relation to hearing the voices and views of people with PMLD.

\section{Welsh policy framework for children with SEN/ALN}

Like England and Scotland, over the past few years, Wales has been involved in reviewing and revising provision for children and young people with SEN. The new system in Wales, which will be implemented from September 2020, still has quite a lot in common with the English system; for example, the new ALN Code like the 2014 SEND code in England (DfE and Department of Health 2015), will cater for children and young people aged 0-25; and when a new code of practice is issued, it will have statutory force. However, there are also important differences; Wales has decided to replace 'Special Educational Needs' and 'Learning Difficulties and Disabilities' with the term 'Additional Learning Needs (ALN)'. This term was previously used in Wales to refer to a much wider group of children, including, for example Young Carers, and Gypsy Travellers (National Assembly for Wales 2006). However, in the ALNET Act the term Additional Learning Needs' is defined exactly as SEN was defined in the 2002 Code of Practice for SEN, with the exception that it applies to children and young people from the ages of 0-25; rather than to those up to the age of 16 only. Wales has also decided that all children with ALN will be entitled to an Individual Development Plan (IDP) (Welsh Government 2017b), whereas in England, only the small percentage of children with the most severe needs are now entitled to an Education Health and Care Plan (EHCP). Given that the Act has not yet been implemented, only its potential impact on children's rights in general and their specific voices in particular can be examined in this paper.

\section{The ALNET Act: participation by children and young people}

The ALNET Act has an ambitious vision:

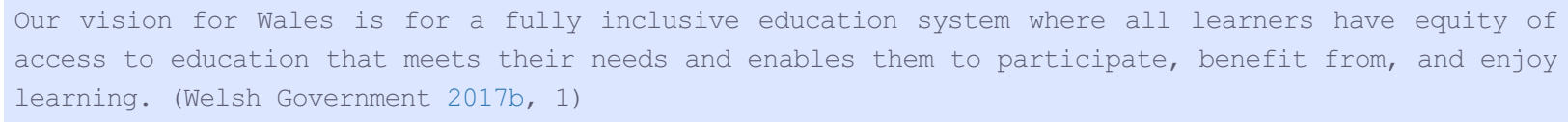

One of the ten core aims which are intended to make this vision a reality is to ensure the increased participation of children and young people: the Act requires that learners' views should always be considered as part of the planning process, along with those of their parents:

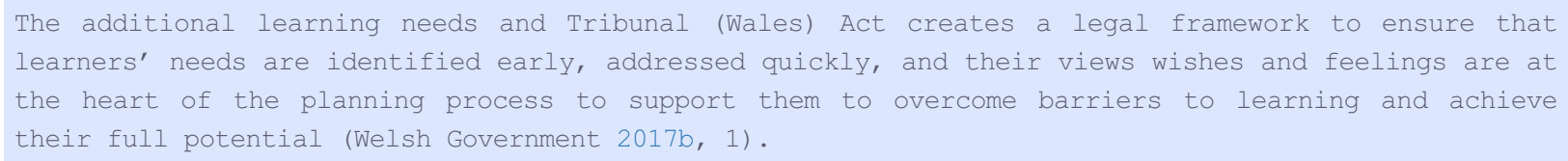

Children and young people with SEN were included in consultation workshops which were held on a relatively early draft of the bill (Welsh Government 2016). It seems unlikely that any of the children or young people who were involved in this consultation had profound intellectual impairments, although children from three special schools that cater for a wide range of learners with SEN, including those with profound and multiple learning difficulties were involved in the consultation process.

On the whole, children were positive about the likely impact of the ALNET Act on their voices being heard. There were also one or two sceptical voices pointing out that if people really wanted to listen to them and involve them they could already be doing this, and a new law might not make a lot of difference. However, the overwhelming majority of children, including all those from special schools, were positive about the idea of being involved in preparing their own IDP. 
However, despite the general optimism of both the children and the adults who took part in the consultation on the draft bill that children's voices would be heard, it seems to me from the little research that there is on this issue that the precedents are not particularly good. Work by Palikara et al suggests that in EHC plans in England, the section which reports the child's perspective was completed in the first person in slightly less than two-thirds of the plans (63.6\%) and even where the first person was used there were often strong indications that it was not the child speaking. Fewer than 1 in 5 plans stated how the child's perspective had been obtained, and often it was stated that parents had filled in this section, as the child's representative. In Palikara's study children whose EHC plans were examined had a variety of needs, and probably included some children with severe and profound learning difficulties, but Palikara et al. did not look at the interaction between how children's voices were collected and type or level of disability, although they do comment that EHC plans for children in mainstream were of higher quality (2018).

Several of the children from special schools, whose answers are cited in the consultation report on the draft ALNET Bill, stated that they did not want their parents involved and a few children/young people expressed concern about the potential for disagreement with parents over aspects of their provision, particularly in relation to the right of appeal. For example one of the young people from the special school sample said:

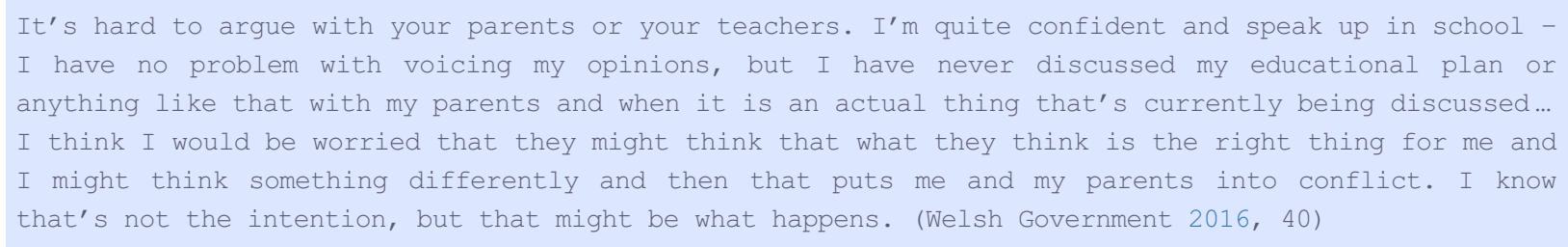

This highlights an issue that has been raised previously by Riddell et al. in relation to Scotland: that it is not clear whose voice will win if children and parents are not in agreement (Riddell et al. 2018) and that this is a particular problem in relation to appeals. This point is also raised by Holtom, Lloyd-Jones, and Watkins (2014) in their evaluation report on the pilot project on children and young people's right to appeal to the Special Educational needs Tribunal for Wales.

\section{Children's involvement in redress mechanisms}

The children's rights impact assessment of the ALNET Act (Welsh Government 2018b) specifically mentions that it aims to strengthen participation by children and young people and their parents, and for children to have a right of appeal and, if they are unable to exercise it for themselves, someone (A 'case-friend') to exercise it on their behalf. In this regard, person-centred planning is emphasised. There is no doubt here of the intention to listen to children's voices, but it may still be difficult for those voices to be heard as distinct from those of their parents or carers. It is too early to say what impact this attempt to strengthen children's rights will have, but in a pilot of young people's right to appeal to the Special Educational Needs Tribunal for Wales, from 2012 to 2014 no young people made an appeal. The evaluation of the pilot (Holtom, Lloyd-Jones, and Watkins 2014) reports that young people were aware of their rights, and as appeals were intended to be a last resort when the system had failed, the pilot was deemed successful. However, both the pilot areas identified that communicating rights to those with complex needs, including those with profound learning difficulties was a significant challenge, and one of the pilot authorities appears to have taken the decision that part of the process of informing children and young people about their rights would be to identify those children whose needs were too complex for them to take part in the process and to whom it was therefore inappropriate to explain their rights. That is most likely to be true where the children concerned have severe or profound intellectual disabilities or serious communication impairments. Perhaps children in this position need an independent advocate appointed, who will attempt to ascertain and communicate their views, using the methods outlined later in this paper. Of course, in the majority of cases, parents may well continue to be the best advocates for their child, but it may still be helpful for the child to have, as it were, a separate voice.

\section{Children's rights and the language of education}

One of the most distinctive features of the Welsh education system is the proportion of children, including those with SEN, who are educated wholly or partly through the medium of Welsh. The home language background of the children in these schools varies considerably; in some schools, almost all the children come from Welsh-speaking homes, while in others, the great majority of the children are from English-speaking homes (Lewis 2006). Except in those areas where almost all primary education is through Welsh, parents have the right to choose the language through which their children are educated. In practice, it is likely that many parents discuss this aspect of school choice with their children, for example at secondary transfer, but children's participation in this choice is not mentioned in the relevant legislation.

Historically, policy in the areas of SEN and the language (i.e. English or Welsh) through which children are educated have been almost entirely separate. However, Chapter 2 of the draft code of practice for ALN (Principles) states that: 
But it is not clear how the child will be enabled to state their language preference, especially if they do not communicate verbally. There is also considerable emphasis within the code on the duty on Schools and services to make Additional Learning Provision available in Welsh. Services must consider whether the child or young person needs ALP in Welsh. If they do, this must be documented in the IDP and services must take 'all reasonable steps' to secure the provision in Welsh. This attempts to address the shortage of services through the medium of Welsh that has been a problem for Welsh-speaking families with children with SEN for many years, for example in relation to speech therapy and educational psychology provision (Welsh Government 2012b). But it is worth noting that there is no reciprocal duty in the ALNET Act for services to consider whether the child or young person needs ALP in English. In parts of Wales, special school and other specialist provision may only be available through the medium of English. The draft code of practice also makes clear that children from Welsh-speaking homes in English Medium provision should be supported by a Welsh-speaking member of staff where necessary. By contrast in parts North Wales, some provision is only available through the medium of Welsh. - So in some areas, primary education is only available through the medium of Welsh, and the only two special schools in Gwynedd which cater for children with SLD and PMLD are Welsh Medium. Of course, it is likely that what happens in practice is far more nuanced than suggested by Local Authority or government policy statements, and anecdotal evidence suggests that practice in terms of the language in which children are supported varies between schools, and in response to individual children's needs.

\section{Research findings on Welsh medium education and children's voices}

There is a considerable amount of research into Welsh Medium education, but very little of it is from a children's rights perspective or seeks the views of children themselves on the language through which they are educated, and children with SEN are almost entirely absent. The research does suggest that children in Welsh medium schools have a generally positive attitude to the Welsh language regardless of whether their home language background is Welsh or English (e.g. Thomas, Apolloni, and Lewis 2014; Owen 2018). Neither Owen's nor Thomas et al's research involves children with SEN; Thomas et al's research does focus on children's views about the use of Welsh and English in school. The 8-11year old children from English-speaking homes in their study expressed broadly positive attitudes towards both Welsh and English, although they were more positive about English. Children in two counties felt that children should be able to use whichever language they preferred at school; interestingly one of these counties was Gwynedd where almost all primary education is through Welsh. Children were also less confident about their abilities in Welsh than in English, and, although the researchers state that 'all children were able to express themselves sufficiently in Welsh' (Italics in original) (Thomas, Apolloni, and Lewis 2014, 354), it is not clear that they could always express their views to their own satisfaction through Welsh.

Evidence of this comes from earlier in the same paper where it is stated that:

In most cases, children responded to the interviewer's questions in Welsh. However, there were two groups of children, one in Conwy and the other in Cardiff, in which some of the children responded exclusively in English throughout the interview. (Thomas, Apolloni, and Lewis 2014, 348)

It seems entirely possible that these children were expressing a preference for conducting the conversation with the researcher in English.

Thomas et al's research was conducted with the aim of identifying potential policy initiatives which could encourage children to use Welsh more, rather than from that of hearing the children's views on immersion education; however it seems that some of the children involved in the focus groups for this study were making a clear statement about the language they preferred to use. Other research does show that children from English-speaking homes who continue in Welsh-Medium education do eventually become fully fluent in Welsh, but that this may not be until they are in secondary school (e.g. Rhys and Thomas 2013).

Enquiries to researchers specialising in Welsh immersion education uncovered only one small unpublished study which includes children with SEN (Lye 2015). In this study, Lye compared children with moderate learning difficulties and typically developing children from Welsh- and English- speaking homes who attended the same mainstream schools. She found that the children with moderate learning difficulties from English-speaking homes were the least proficient in the Welsh language. Lye's research, like that of other researchers in this area, did not compare the results of the participants in curriculum subjects other than English and Welsh.

Brentnall (2009), reviewing more than two decades of research, suggests there is evidence that pupils in immersion settings may not always have sufficient command of the language through which they are being educated to enable them to understand the concepts being taught. Given these findings, and the general view that access to the curriculum is a right for children with SEN, it is, perhaps surprising that there is very little research on how children's access to the curriculum is affected by being educated through a language in which they are not yet fully fluent; and in particular how this impacts children with SEN, who may already 
be struggling to access the curriculum. The study currently being undertaken by Jones looking at access to the curriculum for children with SEN from English-speaking homes being educated through Welsh is an exception (Jones 2018). Jones' early results suggest that the majority of teachers (83\%) in Welsh Medium schools have experience of teaching a learner with SEN from an English-speaking home, and that teachers employ a range of strategies to support these learners to access the curriculum, and these may include using English to communicate with the child, although a few teachers did say that they would never use English. Interestingly, when asked, approximately $50 \%$ of Jones' sample said that they would consider suggesting that a child with SEN should transfer to an English Medium school. However, Jones research does not cover the views of the children themselves. Research on children's views from other areas of the world where children experience immersion education (e.g. Canada) is also extremely scarce. What little literature there is, is divided on whether children who are struggling with the curriculum in a bilingual/ immersion environment cope better if transferred to a school which offers education through their first language (e.g. Cleave et al. 2014; Genesee 2007; Wiss 1989).

\section{Listening to the voices of people with profound and complex difficulties}

Whitehurst (2007) raises the issue of the extent to which we fail to listen to the views of people with profound and complex difficulties, because we lack the resources or expertise to gain those views. Her study is one of very few which reports how views and opinions were obtained. Her study also suggests that considerable expertise and investment in training and resources are required if the views of young people with complex communication needs are to be obtained. Interestingly, it points out that the only way we may be able to obtain the views of some children or young people about particular activities may be by supporting them to participate and then gathering their views about whether they would want to repeat such an experience. Bishton (2007) also reports the methods she used to try and obtain the views of primary school-aged children with SLD and PMLD in detail. Bishton's study was concerned with aspects of school which children did and did not like. She used three different methods to obtain the children's views: an interview through the mediation of a puppet, a diamond ranking game and photographs taken by the children themselves. Triangulation between the different methods suggests that Bishton was successful in obtaining the views of most of the children in her study. Disappointingly, however, she reports that none of her three methods enabled her to obtain the views of either of the two children with PMLD originally involved in the study.

However, other authors are more positive about the possibilities, while still cautioning that there are considerable challenges in both eliciting views and being sure that these have not been unduly influenced by the elicitation strategy. Brewster discusses this issue explicitly in her paper in a special issue of British Journal of Learning Disabilities edited by Lewis and Porter in 2004. She looked at the use of Talking Mats (which uses pre-prepared symbols to assist communication) and cautions that the symbols which are supplied can limit the views expressed, even by individuals who are competent at using AAC (Brewster 2004). In the same special issue, a small-scale case study by Ware (2004) of one boy with a very profound level of learning difficulty suggests that one possible way forward may be through triangulating the views of those who know the child well. Ware showed video footage of Declan engaged in a variety of activities to members of his family and found that their interpretations of his responses did not always agree. These findings do not just highlight the difficulty of interpreting the communication of people with PMLD, but more positively that where the interpretations of several people do agree, they may well be correct.

The findings of a new report by MENCAP and the Challenging Behaviour Foundation (MENCAP and CBF, undated) are also more positive about the possibility of being able to elicit the views of children and young people with Severe or Profound learning difficulties. In one of the projects reported, a carefully prepared for visit to the individual includes a one-to-one interview using talking mats, and other appropriate methods, direct involvement in activities with the individual, observation, and a follow-up questionnaire to family carers. The researchers stress the importance of taking time in preparation and in carrying out the work with the child or young person themselves. Overall this report reinforces Whitehurst's conclusion, that a considerable investment in time and the development of expertise and resources is necessary to enable us to hear the voices of children and young people with severe or profound learning difficulties. Nonetheless, it will still be necessary to heed the cautions expressed by Grove, Bunning, Porter and Olsson two decades ago that ascribing meaning to the communication of a person who is not able to confirm that what they meant will always be a matter of inference that could be incorrect (Grove et al. 1999).

\section{Conclusion}

The case of Wales highlights the complexities to be negotiated around the voices and rights of children (and their parents) in a minority language situation. The research is beginning to show that it is possible to hear the voices of children with PMLD or very severe communication difficulties, and to hear those voices as distinct from those of their parents or caregivers where appropriate. In order to do so, the relevant parties will have to be prepared to expend considerable resources in terms both of time and of training for the practitioners involved. It is possible to enable the voices of these children and young people to be heard more frequently than at present. However, in a minority language situation such as Wales, there are tensions around children's rights and the language of education. In this area, a number of different rights seem to be in conflict; and an examination of the evidence does not (yet) allow a resolution of these conflicts. Children with SEN whose home and heritage 
language is Welsh have a right to be educated and supported through Welsh, and there is a clear obligation in the ALNET Act for Local Authorities to ensure such provision. The obligations on Local Authorities to ensure the right of children with SEN whose home and heritage language is English to be educated and supported through English seems less clear within the legislation. Perhaps that is because, historically, it has been provision through Welsh which has been hard to obtain.

However, it may also be because the rights of the two groups may sometimes either actually or apparently be in conflict, and also conflict with the right of parents in Wales to choose the language in which their children are educated, and with the role of education in ensuring the ongoing health of the Welsh language. Children and parents may have different preferences about the language of education, for a variety of reasons. There is little research which looks specifically at either the outcomes for children with SEN of being in immersion education, and what there is generally lacks sufficient rigour for reliable conclusions to be drawn and there is none which looks at outcomes for children with PMLD. Research on the views of children with SEN about immersion education is almost non-existent. There needs to be research in this area, and such research needs to acknowledge the inherent tensions in the situation and the possibility that different positive outcomes such as inclusion in the local community and achievement of other goals may have to be balanced. Such research needs to include the voices of the children themselves.

\section{Disclosure statement}

No potential conflict of interest was reported by the author[AQ3].

\section{References}

Bellamy, G., L. Croot, A. Bush, H. Berry, and A. Smith. 2010. "A Study to Define: Profound and Multiple Learning Difficulties (PMLD)." Journal of Intellectual Disabilities 14 (3): 221-235. doi:10.1177/1744629510386290.

Bishton, H. 2007. Children's Voice, Children's Rights: What Children with Special Needs Have to Say About Their Variously Inclusive Schools. National College for School Leadership. www.ncsl.org.uk.

Brentnall, J. 2009. "The 2008 National Curriculum for Wales and Additional Language Development." In Education Transactions: Language in Multilingual Wales, edited by H. G. F. Roberts, and W. G. Lewis, 25-46. Bangor: College of Education and Lifelong Learning.

Brewster, S. 2004. "Putting Words Into Their Mouths? Interviewing People with Learning Disabilities and Little/no Speech." British Journal of Learning Disabilities 32 (4): 166-169. doi:10.1111/j.1468-3156.2004.00319.x.

Chzhen, Y., A. Gromada, G. Rees, J. Cuesta, and Z. Bruckauf. 2018. An Unfair Start: Inequality in Children's Education in Rich Countries. Innocenti Report Card 15. UNICEF.

Cleave, P. L., E. Kay Raining Bird, N. Trudeau, and A. Sutton. 2014. "Syntactic Bootstrapping in Children with Down Syndrome: The Impact of Bilingualism." Journal of Communication Disorders 49: 42-54. doi:10.1016/j.jcomdis.2014.02.006.

Department for Education (DfE) and Department of Health. 2015. Special Educational Needs and Disability Code of Practice: 025 years. https://www.gov.uk/government/publications/send-code-of-practice-0-to-25.

Donaldson, G. 2015. Successful Futures: Independent Review of Curriculum and Assessment Arrangements in Wales. Cardiff: Welsh Government.

Genesee, F. 2007. "French Immersion and at-Risk Students: A Review of Research Evidence." The Canadian Modern Language Review / La Revue Canadienne des Langues Vivantes 63 (5): 654-687.

Grove, N., K. Bunning, J. Porter, and C. Olsson. 1999. "See What I Mean: Interpreting the Meaning of Communication by People with Severe and Profound Intellectual Disabilities." Journal of Applied Research in Intellectual Disabilities 12 (3): 190-203.

Holtom, D., S. Lloyd-Jones, and J. Watkins. 2014. Evaluation of a Pilot of Young People's Rights to Appeal and Claim to the Special Educational Needs Tribunal for Wales. Cardiff: Welsh Government. https://gov.wales/statistics-and-research/evaluation-pilot-youngpeoples-rights-appeal-claim-sen-tribunal/?lang=en.

Jones, M. 2016. Research briefing: Welsh-medium education and Welsh as a subject. Cardiff: National Assembly for Wales Research Service. http://www.assembly.wales/research\%20documents/rs16-048/16-048-english-web.pdf[AQ4]

Jones, L. 2018. 'Factors Related to Curriculum Access for Pupils with SEN Learning Through Their Second Language.' Paper presented at The Child's World Conference, Aberystwyth, July 11-13.

Lewis, G. 2006. Welsh-medium Primary Education: The Challenges and Opportunities of the Twenty First Century in Welsh Medium and Bilingual Education. Education Transactions Series B: General. Gwynedd: College of Education and Lifelong Learning, Bangor University.

Lye, C. B. 2015. 'An Exploratory Study of the Linguistic and Cognitive Skills of Welsh: English Bilingual Children with Moderate 
Learning Difficulties in Welsh-Medium Education.' Unpublished PhD thesis, School of Education, Bangor University.

MENCAP and the Challenging Behaviour Foundation. n.d. Valuing the Views of Children with a Learning Disability: Engaging with Children and Young People with Severe or Profound and Multiple Learning Disabilities.

https://www.challengingbehaviour.org.uk/cbfarticles/latest ... /valuingtheviews.html (last accessed 21st December 2018[AQ5]).

National Assembly for Wales. 2006. Inclusion and Pupil Support: Guidance Circular. Circular No: 47/2006. Cardiff: National Assembly for Wales. http://learning.gov.wales/docs/learningwales/publications/121128inclusionen.pdf.

OECD. 2014. Improving Schools in Wales: An OECD Perspective. Paris: OECD. http://www.oecd.org/education/Improving-schools-inWales.pdf.

Owen, J. 2018. 'An Analysis of the Reasons for the Use or Non-use of the Welsh Language Outside the Classroom by Pupils of Welsh Medium Secondary Schools.' Unpublished PhD thesis, School of Education, Bangor University.

Palikara, O., S. Castro, C. Gaona, and V. Eirinaki. 2018. "Capturing the Voices of Children in the Education Health and Care Plans: Are We There Yet?" Frontiers in Education 3.[AQ6]

Rees, G. 2018. Should Wales Be More Like England? What to Keep in Mind When Making Comparisons to Inform Education Policy. Cardiff: Wales Institute of Social \& Economic Research, Data \& Methods (WISERD). https://wiserd.ac.uk/news/should-wales-bemore-england-what-keep-mind-when-making-comparisons-inform-educational-policy.

Rhys, M., and E. Thomas. 2013. "Bilingual Welsh-English Children's Acquisition of Vocabulary and Reading: Implications for Bilingual Education." International Journal of Bilingual Education and Bilingualism 16: 633-656.

Riddell, S., D. Carmichael, N. Harris, J. MacAllister, and K. Wright. 2018. Working Paper 5: Analysis of key Informant Interviews: Scotland. Edinburgh: Centre for Research in Education Inclusion and Diversity (CREID), University of Edinburgh.

Secondary Education and Social Change (SESC). 2018. Briefing paper: Wales. Cambridge: SESC, University of Cambridge. https://sesc.hist.cam.ac.uk/wp-content/uploads/2018/08/Briefing-paper-Wales.pdf.

Thomas, E., D. Apolloni, and G. Lewis. 2014. "The Learner's Voice: Exploring Bilingual Children's Selective Language use and Perceptions of Minority Language Competence." Language and Education 28 (4): 340-361. doi:10.1080/09500782.2013.870195.

Ware, J. 2004. "Ascertaining the Views of People with Profound and Multiple Learning Disabilities." British Journal of Learning Disabilities 32 (4): 175-179. doi:10.1111/j.1468-3156.2004.00316.x.

Welsh Assembly Government (WAG). 2003. laith Pawb (Everyone's Language): A National Action Plan for a Bilingual Wales. Cardiff: WAG.

Welsh Government. 2012a. A Living Language: A Language for Living - Welsh Language Strategy 2012 to 2017. Cardiff: Welsh Government. https://gov.wales/docs/dcells/publications/122902wls201217en.pdf.

Welsh Government. 2012b. More Than Just Words: Strategic Framework for Welsh Language Services in Health, Social Services and Social Care. Cardiff: Welsh Government. www.wales.nhs.uk/sites3/documents/415/web\%20-\%2016184_narrative_e_web.pdf.

Welsh Government. 2016. Participation Workshops with Children and Young People and Parents/carers on the Draft Additional Learning Needs and Education Tribunal (Wales) Bill Consultation: Summary of responses. Cardiff: Welsh Government. https://beta.gov.wales/draft-additional-learning-needs-and-education-tribunal-wales-bill.

Welsh Government. 2017a. Cymraeg 2050: A Million Welsh Speakers. Cardiff: Welsh Government.

Welsh Government. 2017b. Draft Additional Learning Needs Code for Wales. Cardiff: Welsh Government. https://beta.gov.wales/draft-additional-learning-needs-code.

Welsh Government. 2018a. Statistics for Wales: Statistical first release school census results. Cardiff: Welsh Government. https://gov.wales/statistics-and-research/schools-census/?lang = en.

Welsh Government. 2018b. Additional Learning Needs and Educational Tribunal Act (Wales): Children's Rights Impact Assessment. Cardiff: Welsh Government. https://beta.gov.wales/additional-learning-needs-and-education-tribunal-wales-act-childrens-rightsimpact-assessment.

Whitehurst, T. 2007. "Liberating Silent Voices-Perspectives of Children with Profound and Complex Learning Needs on Inclusion." British Journal of Learning Disabilities 35 (1): 55-61. doi:10.1111/j.1468-3156.2006.00405.x.

Wiss, C. 1989. "Early French Immersion May Not Be Suitable for Every Child." The Canadian Modern Language Review 45 (3): 517-529. 